\title{
Agências estetizadas: Juventudes, mobilizações e ativismos em Angola ${ }^{1}$
}

\section{Aesthetic agencies: Youth, mobilizations and activitivisms, the case of Angola}

Frank Marcon ${ }^{2}$

\section{Resumo}

Meu objetivo com este artigo é analisar o contexto das mobilizações e do ativismo em Angola, em um período de emergência da geração digital e compreender o fenômeno em que as formas de ativismo político passaram a ser expressos cada vez mais intensamente de forma estetizada. Pensando nas transformações ocorridas nas manifestações políticas em forma de protesto, desde 2011, analiso o caso de Angola, sobre o qual venho acompanhando as movimentações das juventudes através das redes sociais digitais, sites e blogs. Tenho notado que o visual, o sonoro, a escrita e as performances são linguagens ou agências de ação estética predominantes nas práticas de ativismos juvenis na última década, como no Brasil (Marcon, 2018). Isso significa dizer que entre os jovens as ações políticas são apresentadas de forma cada vez mais plásticas e que as pessoas envolvidas nessas manifestações expressam um grande repertório criativo e comunicativo tanto local quanto global. O caso mais específico que trago aqui é o que ficou conhecido como 15+2 (quinze mais duas), quando durante o ano de 2015 alguns jovens foram presos por protestarem contra o presidente de Angola e tornaram a mobilização em torno do episódio da prisão um mote para expressão de manifestações e protestos, que ganharam grande repercussão em Angola e na comunidade internacional.

Palavras chave: Agências; Estética; Juventude; Ativismo; Angola.

\begin{abstract}
My objective with this article is to analyze the context of mobilizations and activism in Angola, in a period of emergence of the digital generation and to understand the phenomenon of the last decade in which the forms of political activism have passed and to be expressed more and more intensively in a aesthetic way. Thinking about the transformations that have occurred in political demonstrations in the form of protest,

\footnotetext{
${ }^{1}$ Boa parte da pesquisa e das reflexões realizadas para este artigo foram elaboradas incialmente durante um Estágio Pós-doutoral em Lleida, Espanha, realizado com Bolsa Capes, entre os anos de 2015 e 2016. Na ocasião, entre outras atividades de pesquisa envolvendo juventudes e o conceito de agências estetizadas, acompanhei sistematicamente pela Internet os protestos e o ativismo digital que ocorriam simultaneamente na Espanha, no Brasil e em Angola, com algumas incursões de observação direta no Brasil e na Espanha e entrevistas com ativistas angolanos pela internet, com os quais ainda mantenho contato.

2 Doutor em Antropologia pela UFSC. Professor do Departamento de Ciências Sociais na Universidade Federal de Sergipe. Coordenador do Grupos de Estudos Culturais, Identidades e Relações Interétnicas (GERTs). Membro Rede de Estudos e Pesquisas sobre Experiências e Ações Juvenis (REAJ).
} 
since 2011, I analyze the case of Angola, about which I have been following the movements of youths through social networks, blogs and the internet. Since then, I have noticed that visual, sound, writing and performances are the languages or agencies of aesthetic action that are prevalent in youth activism practices, como no caso do Brasil (Marcon, 2018). This means that among young people, political actions are presented in an increasingly plastic way and that the people involved in these manifestations express a great creative and communicative repertoire, both local and global. The most specific case I bring here is what became known as $15+2$, when during 2015 some young people were arrested for protesting the president of Angola and made the mobilization around the prison episode a motto for the expression of demonstrations and protests that have had great repercussions in Angola and in the international community.

Keywords: Agencies; Aesthetics; Youths; Activisms; Angola.

\section{Introdução}

O visual, o sonoro, o escrito e o dramático se tornaram formas de agências estéticas predominantes nas manifestações políticas de protesto e de ativismo na última década, seja no espaço topográfico da cidade ou no ciberespaço. Estou chamando de agências estetizadas aquelas formas de ação, de narrativa e de comunicação que emergem da intencionalidade das expressões sensíveis dos sujeitos, negociadas entre quem as produz e quem as consome, ou entre quem as propaga e quem as recebe, considerando que ambos são produtores de sentido neste processo. Quando relaciono tal agência com a questão do protesto, das mobilizações e dos ativismos contemporâneos, quero dizer que as pessoas envolvidas nessas manifestações expressam e usam um amplo repertório criativo de práticas e símbolos com referências locais e globais e que carregam sentidos políticos intrínsecos nos contextos em que aparecem³ ${ }^{3}$

O fenômeno dos ativismos e dos protestos se transformou largamente na última década quando a internet e as tecnologias móveis também se tornaram as ferramentas, as linguagens e o meio pelo qual passaram a ocorrer. O surgimento do que Castells (2012) e Feixa (2014) - entre outros - denominaram de "era digital" e de "geração digital", respectivamente, possibilitou um cenário em que as pessoas passaram a acessar a informação, o conhecimento e a comunicação de forma mais intensa, livre e aleatória, à medida que o acesso e a absorção de tecnologias digitais

\footnotetext{
${ }^{3}$ Estou utilizando a expressão repertório no sentido dado por Charles Tilly. Citando Tilly, Alonso (2012, p. 26) sintetiza o conceito: "A palavra repertório identifica um conjunto limitado de rotinas que são aprendidas, compartilhadas e postas em ação por meio de um processo relativamente deliberado de escolha. Repertórios são criações culturais aprendidas, mas eles não descendem de filosofia abstrata ou tomam forma como resultado da propaganda política; eles emergem da luta. [...] Em qualquer ponto particular da história, contudo, elas [as pessoas] aprendem apenas um pequeno número de maneiras alternativas de agir coletivamente".
} 
também se tornou mais ampla e fácil, além de mais criativa e mais compreendida, principalmente por uma geração de jovens que desde muito cedo se socializou e se educou em meio aos dispositivos tecnológicos móveis, em meio às linguagens digitais e diante das formas de cognição em que a imagem, o grafismo, o som, a oralidade e o texto digital (quase sempre de mensagens curtas) passaram a compor uma infinidade de possibilidades de comunicação, sensações e aprendizados.

Manuel Castells (2012) disse sobre as manifestações de 2011, no livro Primavera Árabe y Los Indignados, que tais manifestações começaram nas redes e logo a seguir as pessoas sentiram a necessidade de assumir os seus papéis ativos nas ruas. Acrescento que esta dinâmica se ampliou e intensificou tal relação intrínseca, passando não só a ser um fenômeno das redes para as ruas, mas também das ruas para as redes, em que mais pessoas se envolveram e se implicaram politicamente. É importante frisar que não só as manifestações e ativismos nos espaços da cidade ganharam enorme destaque e passaram a fazer parte do cotidiano das pessoas, mas principalmente as manifestações e ativismos comunicados ou realizados na internet foram as que permitiram maior visibilidade e também exerceram o papel de meio pelo qual as pessoas convocam, informam e protestam atualmente. A proliferação de recursos tecnológicos móveis transformou a todos e todas em potenciais produtores de conteúdo e por sua vez ampliou a visibilidade e a diversidade das formas de manifestação política. Este fenômeno ocorreu em várias regiões e países do mundo, incluindo países da África subsaariana, embora o contexto social, político e econômico vivido em Angola, por exemplo, tenha evidenciado certos contornos singulares às experiências das juventudes, como tratarei adiante. Por ora, destaco que entre as particularidades está o fato de que pelas circunstâncias políticas, principalmente o medo da repressão governamental, não houve grandes multidões nas ruas do País durante as primeiras manifestações, embora certa regularidade e intensidade do ativismo e certa convergência de pautas em torno da reinvindicação geral por democracia tenha ganho um destaque marcadamente geracional e os usos das tecnologias digitais tenham sido um recurso imprescindível.

Após o Occupy Wall Street, a Primavera Árabe, os Indignados na Espanha, as Jornadas de Junho no Brasil e as primeiras manifestações dos Revús em Angola ${ }^{4}$, entre outras, surgiram diferentes modalidades de recursos expressivos disponíveis ao agir político, que demonstraram um modo de viver e compreender a política que está relacionado às transformações ocorridas no

\footnotetext{
${ }^{4}$ Como descreverei adiante, Revús é a denominação pela qual ficaram conhecidos e se fizeram conhecer os jovens que aderiram as manifestações de 2011 contra o governo, em Angola, influenciados pelo espírito da chamada Primavera Árabe.
} 
cotidiano das pessoas em termos sociais, econômicos e tecnológicos. As manifestações e protestos de rua passaram a contar com a visibilidade de várias agências individuais; com mais linguagem corporal; com maior ênfase na pluralidade de modos de pensar, compreender e dizer sobre o processo político em que estão envolvidas (Marcon, 2018). O que trago neste artigo é a sistematização dos registros que realizei sobre o curso de dois dos momentos mais intensos das manifestações políticas das juventudes em Angola na última década, procurando compreender as particularidades deste fenômeno geracional do ativismo e suas implicações para as juventudes de forma geral e em particular a angolana.

\section{Os Jovens Revolucionários em Angola - Revús}

Tomando o caso específico de Angola e suas particularidades, pouco visíveis nos cenários globais midiáticos dos protestos e do ativismo nos últimos anos, mas com atividades muito presentes nas redes sociais ${ }^{5}$, proponho aqui desenvolver alguns dos meus argumentos sobre o quê denomino de agências estetizadas do protesto (Marcon, 2018), como fenômeno contemporâneo das juventudes da geração digital, que aos poucos foi também se tornando mais predominante no modo de fazer política entre outros grupos etários. É importante destacar que manifestações políticas de rua contra o governo foram sempre coibidas em Angola, invisibilizadas na mídia ou fortemente reprimidas, especialmente até o início desta década. Lembrando que desde 1975 o país é governado pelo mesmo partido MPLA e desde 1979 até muito recentemente, 2017, teve um mesmo presidente: José Eduardo dos Santos. Também é importante registrar que até 2002 o país viveu um longo período de guerra civil e nos primeiros anos após o fim dos conflitos, mesmo com o pluripartidarismo, a burocracia do Estado continuou sendo ocupada hegemonicamente pelos mesmos grupos e pessoas, restringindo-se muitos dos direitos políticos à sociedade civil em geral, seja pelas consequências econômicas ou sociais dos efeitos do longo período de guerra, seja pela desconfiança ou violência das instituições com relação aos opositores do governo.

Ao contrário das manifestações na Espanha (em 2011) e no Brasil (em 2013), por exemplo, em Angola as primeiras manifestações da década foram tímidas em números, embora agitadas por ações violentas por parte da polícia. Na África Subsaariana, além de Angola, uma versão dos protestos da Primavera Árabe também ocorreu em países como África do Sul, Burkina Faso, Cabo

\footnotetext{
${ }^{5}$ As questões políticas em Angola ganham algum espaço na imprensa em língua portuguesa países como Portugal e Brasil, devido ao idioma oficial do país, mas também pelas relações históricas dos tempos do colonialismo e pelas atuais relações econômicas, diplomáticas e de imigração com tais países.
} 
Verde, Moçambique e Senegal. Embora as realidades políticas sejam distintas para cada caso, as pautas do autoritarismo, da corrupção e da crise social e econômica foram fatores de indignação comum, bem como a ampliação do acesso e a apropriação das tecnologias móveis e da internet fora considerado um fenômeno transformador das agências dos jovens em tais manifestações. De modo geral, os protestos tiveram a característica de serem ações dispersas, implicadas por problemas sociais do cotidiano, articuladas através das redes sociais, mas sem organicidade de sindicatos, partidos ou movimentos associativos.

O surgimento da série de protestos iniciados em Angola a partir de 2011 esteve relacionado ao empobrecimento sistemático da maioria da população angolana, em grande parte dos jovens, em contrapartida ao enriquecimento ilícito de uma classe de políticos e suas famílias. A crise da economia mundial atingiu o país (com a queda do valor mundial de seu principal produto, o Petróleo) e os mais de 30 anos de autoritarismo de um único presidente no poder tornaram-se fortes elementos para questionar a ausência de democracia de fato e a falta e o respeito a liberdades individuais, principalmente a liberdade de expressão. ${ }^{6}$ Nas ruas surgiram faixas, palavras de ordem com frases clamando por "democracia agora” e a "saída do Presidente José Eduardo dos Santos", ao mesmo tempo em que grupos de jovens criavam mecanismos de protestos através do ativismo digital. Estes jovens passaram a ser denominados nas mídias sociais e nas redes sociais por "Revús".

Foram várias as ações mobilizadas por tais jovens entre 2011 e 2015, reprimidas com violência, com prisões e desaparecimentos. A primeira destas manifestações foi convocada online por meio de sites e redes sociais (Facebook e YouTube) e sua convocação foi veiculada no site "Movimento Revolucionário", para o dia 7 de março de $2011^{7}$, sendo assinada por "personagens fictícios", como estratégia da não responsabilização individual dos seus mobilizadores. As informações circularam na internet e por meio de mensagens no celular, até que durante um show de música (no Cinema Atlântico), no dia 27/02/2011, um grupo de jovens rappers e bboys lançou a provocação ao público e reforçou a necessidade de se realizar um grande protesto em Angola, propondo que as pessoas se juntassem à manifestação que estava circulando pela internet. No dia 7 de março de 2011, compareceram ao ato 17 jovens, pessoas da imprensa e um grande aparato policial para controlar a manifestação. A repercussão nas mídias e nas redes sociais tornou o protesto e suas pautas ainda mais conhecido. ${ }^{8}$

\footnotetext{
${ }^{6}$ A rede jornalística Al Jazeera produziu a reportagem Activate - Angola: Birth of a Movement, em 2012, sobre o início das manifestações em Angola, a partida das influências da Primavera Árabe, ver: https://www.youtube.com/watch?v=VbwzyirPhM Último acesso em 12/08/2020.

7 Ver: http:/ / novarevolucaoangolana.yolasite.com/ Último Acesso em 12/8/2020

8 Sobre datas e informações sobre tais acontecimentos, pode ser consultado o livro de Manoel e Fortuna (2012).
} 
A partir daí, as manifestações se tornaram mais regulares, incluindo a manifestação de 2 de abril de 2011, justificada como pacífica e apartidária, realizada no Largo da Independência, com o lema "Liberdade de Expressão em Angola".' Várias destas manifestações foram reprimidas e em muitas delas alguns ativistas foram presos. Além disto, muitas outras estratégias de coação foram realizadas contra tais atos, como por meio da polícia e grupos de homens não identificados agindo pró-governo, que passaram sistematicamente a dispersar violentamente os manifestantes, a exemplo do que ocorrera em outra manifestação, em 3 de setembro de 2011. Estas formas de reação contra os protestos tinham o objetivo de intimidar os manifestantes e recolher ou desligar os aparelhos eletrônicos com os quais eles realizavam registros dos atos em fotos e vídeos para transmitirem através da internet. Além da violência, da intimidação e da arbitrariedade, também se tornou uma estratégia governamental criar eventos a favor do presidente e do governo, nos quais algumas pessoas eram pagas para estarem nos mesmos dias e locais que os ativistas, mas exaltando os símbolos nacionais e o apoio ao presidente, muitas vezes com a presença da JMPLA, a juventude do partido. Outras vezes, autoridades policiais bloquearam o acesso aos locais das manifestações, como os acessos ao Largo da Independência, muitas vezes escolhido pelos manifestantes por ser um importante espaço simbólico da política nacional, em que se realizam diferentes eventos e atividades oficiais, onde foi erguido pelo Estado um monumento representativo da luta contra o colonialismo, contra o racismo e pela liberdade do povo angolano. A escolha do Largo da Independência pelos manifestantes foi ao mesmo tempo uma tática de identificação política unificadora das manifestações de indignação popular - pelos significados simbólicos representados pelo monumento-, mas também uma tática de visibilidade pela centralidade urbana e pelo intenso fluxo de pessoas e veículos no local, por estar próximo de grandes escolas, edifícios e locais públicos, incluindo instituições governamentais. Pelos mesmos motivos, o governo passou a coibilos com força naquele lugar.

As recorrentes manifestações de 2011 passaram a preocupar o governo. O próprio presidente José Eduardo dos Santos, em discurso no dia 15 de abril de 2011, durante a abertura do congresso do MPLA, acusou os jovens Revús e a Internet de serem a causa de descontentamento, incompreensão e motins em Angola e na África em geral, condenando publicamente e de forma moralizadora as manifestações que pediam alternância no poder e democracia no País ${ }^{10}$. Vários

\footnotetext{
${ }_{9}^{9}$ Ver: https://www.youtube.com/watch?v=lwZESB7UiBo (Último Acesso em 10/9/2020)

${ }^{10}$ Ver discurso na íntegra: http://www.angop.ao/angola/pt_pt/noticias/politica/2011/3/15/Discurso-PresidenteJose-Eduardo-dos-Santos-reuniao-Comite-Central,e545cbc5-1a17-43e7-a00a-f7f3d1f3dbd4.html Último acesso em $12 / 08 / 2020$
} 
setores governamentais trabalharam a contrainformação e a desmobilização das manifestações, tentando criar certo pânico moral sobre o surgimento destes atos, buscando sucessivamente construir lógicas de controle para desencorajar, desmantelar e conter as manifestações, com estratégias de intimidação, criminalização e desconstrução da força simbólica das reivindicações.

Em 2012, ocorreram eleições em Angola e outras manifestações voltaram a acontecer sempre reprimidas, intimidadas e dificultadas pelo governo. Para além dos protestos, os Revús criaram uma Campanha de Observação Paralela às Eleições de 2012 e em seguida denunciaram ter ocorrido fraudes nas eleições, mas o fato é que o MPLA foi o grande vencedor do pleito e José Eduardo dos Santos voltou a ser conduzido à presidência pelo voto indireto, dadas as especificidades do sistema eleitoral em Angola. Várias manifestações continuaram acontecendo e em 2013 ocorreu o desaparecimento e assassinato de dois manifestantes e com isso outros ativistas mobilizaram novos protestos contra a violência do Estado e pela liberdade de expressão. Em 2014, as manifestações continuaram, o ativismo aumentou, o descontentamento e as formas de intervenção continuavam crescentes e ativos tanto nas ruas quanto na internet, embora sempre intimidados, isolados, criminalizados e judicializados.

No livro Os Meandros das Manifestações em Angola, os autores Manoel e Fortuna (2012) destacam que muitos dos envolvidos nas primeiras manifestações eram jovens, estudantes e/ou rappers que de algum modo se sentiram estimulados pelas manifestações de rua que estavam acontecendo em países do mundo árabe, que levou multidões as ruas contra governos autoritários na Síria, no Egito e na Tunísia, durante a chamada Primavera Árabe. Nas palavras dos autores e também ativistas (Manoel e Fortuna, 2012), foram sete as razões pelo início dos protestos em Angola: " $\left.1^{a}\right)$ O empobrecimento sistemático do povo angolano e em contrapartida, o enriquecimento ilícito da elite dominante e seus familiares; $2^{\mathrm{a}}$ ) Prepotência, arrogância manifesta dos dirigentes do partido governante; $3^{a}$ ) Nepotismo e Oligarquia; $4^{a}$ ) Desfalques e roubos sistematizados aos cofres do Estado angolano; $5^{a}$ ) Péssimas condições de vida das populações angolanas; $6^{a}$ ) Os 32 anos no poder (do presidente José Eduardo dos Santos) e, $7^{\text {a }}$ ) A exclusão dos angolanos a favor dos estrangeiros;” (Manoel e Fortuna, 2012, p. 22). 


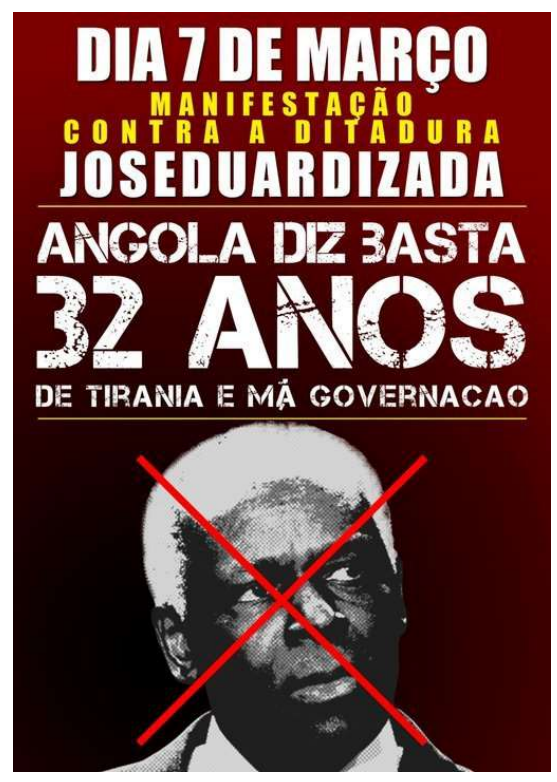

Figura 1: Cartaz Publicado na Internet para Convocação da Manifestação de 07/03/201111

Manoel e Fortuna (2012) destacam a importância das redes sociais e dos telefones celulares nas mobilizações dos autodenominados "Jovens Revolucionários" (ou Revús, como passaram a ser conhecidos). Neste sentido, é importante destacar que nos últimos anos a expansão da tecnologia de conexão e tráfego de dados $3 \mathrm{G}$, depois $4 \mathrm{G}$, e o aumento mundial da cobertura permitiram um crescimento sem precedentes no acesso à internet por parte de jovens nos diferentes países africanos. ${ }^{12} \mathrm{O}$ uso de suportes móveis de tecnologia, como celulares, smartphones, bem como máquinas fotográficas e câmeras de vídeo digitais se tornaram também instrumentos de protesto. Além disto, os smartphones se tornaram aparelhos cada vez mais comuns e mais populares no ativismo, por agregarem múltiplas funções de comunicação, de acesso à informação, de localização, de compartilhamento, de captação e de edição de imagem e de som. Estes suportes passaram a ser utilizados tanto como ferramenta de comunicação e consumo de informação, quanto como parte

\footnotetext{
${ }^{11}$ Fonte: http:/ / novarevolucaoangolana.yolasite.com/ Último Acesso em 12/8/2020

12 Sobre o impacto das tecnologias de internet, das redes sociais e do acesso a telefonia móvel na vida política dos países africanos na última década, ver reportagem do El País: http://elpais.com/elpais/2016/02/29/planeta futuro/1456752494 877876.html Último acesso em 12/08/2020. Em 2016, o Jornal El País, publicou um caderno especial "El África Conectada", trazendo informações individualizadas por País e a conectividades nos mesmos. Sobre Angola, dizia: "Población total:24.227.524; Media de edad:18,0; Nivel de escolarización (\% de menores de 15 años): 71,10; Población por debajo del umbral de la pobreza: 40,50\%; Líneas de teléfonos móviles para cada 100 habitantes: 63,48; Usuarios de internet: 26\%; Usuarios de Facebook: 3.300.000. https://elpais.com/especiales/2016/planeta-futuro/africa-conectada/map.php Último Acesso em 12/08/2020. Para mais dados sobre acesso a internet e a telefonia móvel em Angola, ver reportagem do Jornal de Angola, de 2019: http://jornaldeangola.sapo.ao/economia/sete-milhoes-de-cidadaos-utilizam-internet-no-pais Último acesso em $12 / 08 / 2020$.
} 
das técnicas produtoras de estéticas criativas que possibilitaram expor outras agências e outras visibilidades dos modos de se sentir, de se entender e de se expressar o político.

Entre as estratégias dos ativistas, esteve o forte uso dos recursos digitais através dos quais eles passaram a publicar denúncias contra má governança, a fazer discussões políticas e a produzir charges críticas e sarcásticas contra o presidente. Também foi intensa a produção de vídeos informativos, vários memes e diversas músicas de protesto. Como dito acima, muitos dos jovens envolvidos nestas ações se iniciaram nas redes de socialização e ativismo na internet a partir da produção e do consumo musical, principalmente do envolvimento com o rap, que teve um papel importante como manifestação de mensagens de protesto e pela expertise e dimensão do seu modo de fazer independente.

Através do uso das redes sociais e blogs também foram se constituindo canais independentes de comunicação e produção de informação e ativismo, que se tornaram meios pelos quais a desobediência civil e as várias formas de escracho contra os governantes articularam suas manifestações de protestos nas ruas e no ciberespaço. Os sujeitos dessas manifestações se tornaram produtores do próprio conteúdo de informação, que passou a ganhar repercussão e autonomia nas redes de comunicação digital e, mesmo que restritas a grupos específicos de empatia, passaram a fazer parte do debate público, destoando das narrativas dos órgãos de mídia governamental ou de grandes empresas privadas. Acessar, criar, gravar, filmar, fotografar, escrever, editar, samplear, mimetizar e compartilhar se tornaram práticas comuns do ativismo dos Revús e possibilitaram novas modalidades de agências políticas que passaram a ser expressas por meio de uma infinidade de linguagens e de suportes de mídias dominados por eles.

Destaco aqui, entre outras iniciativas, a página web denominada "Central Angola 7311”, na qual alguns dos mobilizadores das primeiras manifestações estiveram envolvidos e que se manteve por anos como um canal bastante ativo e como referência das primeiras manifestações contra o governo entre os jovens em Angola, produzindo conteúdo e informação, utilizando-se da ironia, do humor, do escracho e de efeitos dramáticos como forma alternativa de informação e debate sobre as questões sociais do país, com o intuito de provocar e sensibilizar a população para a participação política. O nome Central 7311 foi escolhido como uma referência simbólica à data da primeira manifestação organizada em 7 de março de 2011, já referida acima, e é considerada um marco simbólico das manifestações que a sucederam. A Central Angola 7311 passou também a dominar e a nomear uma variedade de ferramentas digitais na internet com contas no YouTube, Facebook, Twitter e outras redes sociais, se tornando uma marca reconhecida das plataformas dos Revús. 
Diz na página de apresentação do site:

"Aqui publicaremos não só a correspondência com o Governo Provincial de Luanda como também alguma informação independente, fora da redoma dos nossos viciados meios de comunicação social, na linha do chamado "jornalismo cidadão". Publicaremos igualmente alguns textos de opinião de diferentes colaboradores e estamos abertos a outros textos que vão ao encontro do que temos vindo a defender. A Central 7311 pretende ser somente um espaço de convergência, de troca de ideias e de comunicação dessa juventude, dessa minoria(?) que está descontente, cansada e revoltada com a situação social e política em Angola." 13

A “Central 7311" surge também com a proposta de promover a memória de um marco político inaugural para aqueles ativistas. Não só a manifestação de 07 de março de 2011, mas tudo que ele poderia representar como ato de transformação na forma de fazer política no País, estendendo sua existência como continuidade, movimento e marca das transformações geracionais que estavam ocorrendo no País, que mesmo sem uma pauta convergente sobre economia ou sobre o direcionamento político ideal, convergiam na crítica radical contra o predomínio da ordem governamental vigente, que afetava suas vidas e de toda uma geração alijada de direitos sociais, economicamente precária e distante da representação política.

Para Alcinda Honwana (2014), as manifestações ocorridas nesta década nos países da África Subsaariana, foram a reação dos jovens contra uma interminável condição de espera sobre a expectativa de autonomia e de futuro. Sem perspectiva de autonomização e sem direção eles passaram a se aproximar por motivos comuns em torno do que não querem, ao invés de projetos e aspirações que os unam ideologicamente. $\mathrm{Na}$ análise de Honwana (2014), nessa condição interminável de espera por uma vida plena, de reconhecimento social, de acesso a recursos econômicos e de força política, os jovens não se sentem pertencentes, acolhidos ou integrados aos modelos de ordem social vigentes, como sujeitos capazes de construir sua própria autonomia esperada pela condição adulta e procuram seus próprios meios para fazê-lo, subvertendo as autoridades e o aparato legal instituído. Como contraponto, as tecnologias digitais possibilitaram em alguma medida a agência política, econômica e social de uma maioria jovem que enfrentava e enfrenta as dificuldades de se constituírem como sujeitos plenos em meio a contextos de extremas dificuldades e escassez (Marcon e Tomás, 2012).

\footnotetext{
13 Ver: https://centralangola7311.net/about/ Última consulta em 10/9/2020.
} 


\title{
O Caso 15+2 e a Estetização do Ativismo
}

\begin{abstract}
"Sou o Hitler Jessy Tshikonde o mesmo que Hitler Samussuku, nasci na província do Moxico e a minha vida foi entre esta província e a capital (Luanda), mas acabei por viver mais na última. Sou formado em Ciência Política pela Universidade Agostinho Neto, sou rapper, activista, promotor de manifestação e faço parte de uma geração que luta para alternância política e por mais liberdades em Angola. O nosso país é bastante partidarizado, temos um regime autoritário que se instalou em 1975 e perdura até hoje. Para mudar alguma coisa, usamos a música, as nossas contas nas redes sociais Facebook, Whatsapp e Youtube, procurando de certa forma influenciar o processo de mudanças com vista a garantir uma Angola melhor para a próxima geração. Actualmente fundamos o Movimento Jovens pelas Autarquias que tem procurado pressionar as autoridades sobre a importância das autarquias locais para o desenvolvimento dos municípios. Visa resgatar a cidadania e estimular os cidadãos na vida pública." 14
\end{abstract}

Entre os anos de 2015 e 2017, o ativismo dos Revús ganhou maior visibilidade com o caso que se tornou internacionalmente noticiado e conhecido como $15+2^{15}$. No dia 20 de junho de 2015, um grupo de jovens foi detido quando se reunira para discutir o livro de Domingos de Castro, Ferramentas para destruir o ditador e evitar nova ditadura - Filosofia de Libertação de Angola, inspirado em outra obra Da ditadura à Democracia, de Gene Sharp. Na ocasião em que discutiam o livro, as instalações foram invadidas pela polícia e o grupo foi preventivamente acusado de conspirar um golpe de estado. O caso ficou conhecido por $15+2$ por alusão ao envolvimento inicial de quinze jovens do sexo masculino e posteriormente o acréscimo à prisão de duas jovens do sexo feminino. ${ }^{16}$ Durante a prisão e durante um ano de processo judicial repleto de percalços, concluído em julho de 2016, do qual participou o jovem da narrativa acima, o caso ganhou repercussão nacional e internacional por meio das redes sociais, mídias digitais e protestos de rua em apoio aos ativistas.

\footnotetext{
${ }^{14}$ Trecho de conversa realizada pelo autor deste artigo com Hitler Tshikonde, em 2020, pelo aplicativo de mensagens whatsapp. Outra entrevista foi realizada em 2016, quando Hitler descreve seu envolvimento no processo 15+2.

${ }^{15}$ Entrevistei ou conversei por e-mail, WhatsApp ou Messenger com alguns dos $15+2$, a quem agradeço a atenção por compartilharem suas histórias e outras contribuições.

${ }_{16}$ São eles e elas: Domingos José da Cruz, Henrique Luaty da Silva Beirão, Nuno Álvaro Dala, Manuel Chivonde Baptista, Afonso Mayenda João Matias, Benedito Jeremias Dali, Inocêncio António de Brito, Sedrick Domingos de Carvalho, Albano Evaristo Bingo Bingo, Arante Kivulu Italiano Lopes, Hitler Jessy Tshikonde, Fernando António Tomás, Nélson Dibango Mendes dos Santos, Osvaldo Sérgio Correia Caholo, José Gomes Hata, Laurinda Manuel Gouveia e Rosa Kusso Conde. Para mais informações, ver reportagem "É Proibido Falar em Angola", no endereço eletrônico da Agência Pública http://apublica.org/2015/10/proibido-falar-em-angola/ por Elisa Capai e Natalia Viana. Último acesso em 12/08/2020. O Jornal Maka Angola publicou também uma pequena bibliografia dos ativistas, em https://www.makaangola.org/2015/07/jose-eduardo-dos-santos-tem-medo-de-livros-e-de-miudos/ Acesso em $12 / 08 / 2020$.
} 
Durante a prisão, os Revús mantiveram ativas várias manifestações de protesto contra o governo. Dentre as ações: 1) continuaram utilizando as redes sociais como Youtube, Twitter e Facebook para difundir sua visão injusta dos acontecimentos, para denunciar e protestar contra o processo e a prisão dos ativistas; 2) realizaram concertos musicais, atos, vigílias e passeatas contra a prisão sem julgamento dos $15+2$; 4) utilizaram sites alternativos de notícias locais e correspondentes internacionais, com eventos que chamaram a atenção do público, mantendo em evidência a atenção da imprensa e a circulação de imagens e informações sobre o caso; 5) criaram inúmeras formas de manifestação reunindo pessoas nas praças e ruas de Angola e de outros países do mundo (Brasil, França, Portugal, entre outros), sempre com registros visuais e divulgação de imagens e informações sobre os eventos; 6) alguns dos 15+2 fizeram Greve de Fome, tentando visibilizar a causa e sensibilizar a opinião pública, os organismos internacionais e o governo, o que fora divulgado amplamente pelas redes sociais e mídias digitais independentes; 7) durante o julgamento, os presos se apresentaram diversas vezes em juízo satirizando seus julgadores ou enviando mensagens políticas maquiando-se ou adicionando as suas roupas mensagens contra o que definiam como prisão política, com o intuito de assinalar o seu protesto e ganhar publicidade durante a cobertura da imprensa; 8) os presos criaram memes com o seus próprios rostos pintados de palhaço ou usando perucas satirizando o governo e seus julgadores, substituindo estas por suas imagens de perfis nas redes sociais; 9) escreveram relatórios de dentro da prisão e publicaram nos seus canais da internet sobre as condições dos presídios e dos presos em geral, tornando visíveis outros personagens e outros problemas, que muitas vezes se fizeram esquecidos pelo governo, o que transformou a estada do grupo nas prisões um incomodo político, ao invés de silenciá-los; 10) durante a prisão escreveram diários sobre suas experiências na cadeia e durante o julgamento as publicaram por meio de redes sociais, visibilizando publicamente suas existências e constrangendo de algum modo as possibilidades de ações ilegais das autoridades ou de agentes que a mando criminoso os colocassem sob algum tipo de risco de vida. Todas estas formas de ativismo e protesto tiveram grande repercussão local e internacional e após um longo período de julgamento, e um ano depois de serem presos, foram libertados. 


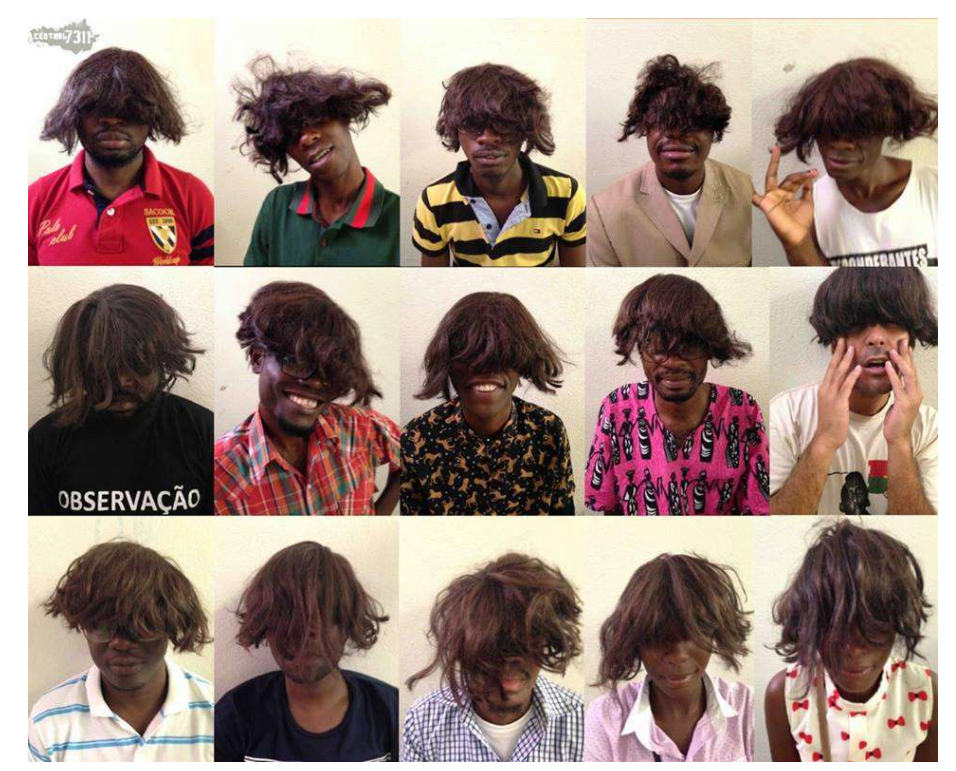

Figura 2: Meme publicado no site Central 7311, com os presos satirizando uma das Juízas do caso 15+2

Por meio de ferramentas digitais, edições caseiras e redes sociais, os ativistas improvisaram, criaram oportunidades de conscientização, visibilidade, reconhecimento e apoio dentro e fora do país. O efeito do ativismo em torno do " $15+2$ ” tornou as demandas dos Revús ainda mais visíveis e a tentativa do governo de pará-los com a prisão teve o efeito inverso de difundir ainda mais as motivações e ações do grupo. Os recursos mais recorrentes entre eles, como práticas de protesto, advinham das habilidades com as tecnologias digitais e com as linguagens comunicacionais. Fotografar, filmar, cantar, desenhar, pintar, escrever, atuar, editar, compartilhar e publicar, com a intenção de responder, denunciar, informar e agir politicamente fora, até então, uma prática comum que demarcara uma tensão entre formas geracionais distintas de atuação política entre os Revús e o governo. O que demonstra o quanto em tal formato de ativismo e protesto as agências individuais e coletivas são mais barulhentas, difusas e fluidas, mais dinâmicas e imprevisíveis, e pouco preocupadas com a técnica e a linguagem formal de apresentação ou com a racionalidade, a hierarquia e a clareza das formas comunicativas.

Os $15+2$ acabaram construindo a própria narrativa sobre suas trajetórias, sobre suas motivações e sobre o modo de mobilização do grupo, tornando a repercussão de suas ações e suas justificativas ainda mais visíveis, possibilitando que muitos outros jovens e parte da população em geral aderissem as suas pautas pela democratização do País, pela necessidade da alternância do poder, pelas investigações contra corrupção e pelas liberdades individuais e coletivas de reunião e expressão; fragilizando em alguma medida a estabilidade de certas lideranças, especialmente a do presidente José Eduardo dos Santos. Em várias ocasiões, durante ou após a prisão, os 15+2 
construíram suas narrativas sobre si e nos contaram como se viram no processo e o que pensavam e pensam de tais episódios (a exemplo da narrativa de Hitler, que abre este capítulo, mas também da parte de outros deles, como, por exemplo, a publicação do livro Sou Eu Mais Livre, Então, do ativista Luaty Beirão, sobre as condições e a experiência da sua prisão política; além das outras narrativas disponíveis na internet nas próprias redes sociais dos ativistas ${ }^{17}$ ). Outras vezes, construíram suas próprias narrativas também coletivas sobre o que entendiam e entendem representar ou terem representado politicamente para o País, como no texto assinado por eles e elas, durante uma palestra coletiva à imprensa, em agosto de 2016, publicada no sítio eletrônico da Central 7311. O texto ressalta a diversidade social dos participantes e as diferenças nas opiniões políticas, embora destaque o ponto comum da luta contra o autoritarismo e a ideia de que juntos advogavam por algo maior, que seria a vontade coletiva de transformação social em Angola.

\begin{abstract}
"Somos jovens de vários extratos sociais, de vários níveis de formação e também sem formação nenhuma, apartidários ou partidários, religiosos ou ateus, empregados ou desempregados, formando-se ou autodidatas, somos filhos de camponeses e de abastados, estamos na zunga e nos escritórios também, vivemos no musseque ou na cidade, enfim, somos nós, somos vós, somos todos nós! Somos a manifestação dos anseios não saciados do nosso povo. Um grito de mudança que não se quer calar". ${ }^{18}$
\end{abstract}

Tal manifestação pública dos $15+2$ parece exemplificar as duas facetas da expressão da agência dessa geração em Angola. No plano da experiência individual, o que me parece uma questão central é a possibilidade e o desejo de participação política direta de tais jovens como sujeitos de seus destinos, além da satisfação pessoal pelo envolvimento com a ação política, como forma de reivindicação de sua existência em uma sociedade que até então anulava suas possibilidades de autonomia, inclusive como sujeitos políticos. No plano coletivo, a principal característica de tais manifestações foi a visibilidade das diferentes pautas dos seus ativismos, destoando das narrativas hegemônicas das grandes corporações informacionais e das instituições políticas legitimadas pelo Estado, além de especialmente abranger genericamente temas como democracia, justiça social e liberdade de expressão. Tais questões ampliaram e diversificaram a atuação, a visibilidade e a participação ativista em Angola, evidenciando a agência das juventudes e trouxeram transformações

\footnotetext{
${ }^{17}$ Ver, por exemplo, a narrativa na página de Luaty Beirão, no facebook, que no dia 20/06/2016, registrando um ano de prisão, publica a sua versão dos acontecimentos. O que fora feito sistematicamente durante todo o período em que se mantivera na prisão: https://www.facebook.com/luatybeirao/posts/601389296689194:0 Último acesso em $12 / 08 / 2020$.

18Ver: https://centralangola7311.net/2016/08/19/o-caso-15duas-uma-longa-cronologia/ Último Acesso em $10 / 9 / 2020$
} 
políticas significativas que complexificaram ainda mais as disputas pela multiplicidade de pautas e de posicionamentos até então pouco institucionalizados.

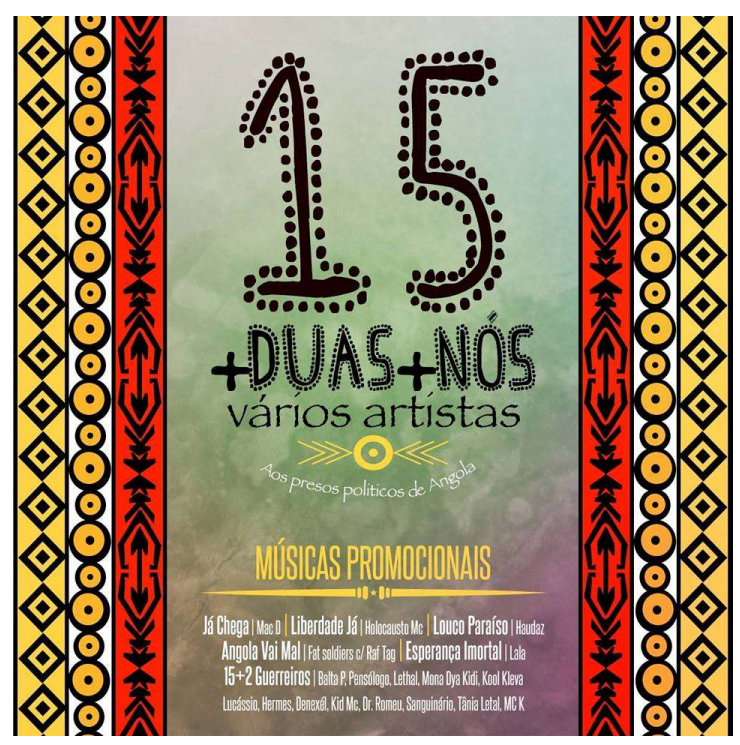

Figura 3: Fac-Símile de Capa do CD-Room produzido como Campanha pela Libertação dos 15+2

Em Angola, a atuação dos Revús e a questão em torno da prisão e da libertação dos $15+2$ impulsionou o ativismo e os protestos nas ruas e na internet eles continuaram clamando pelo fim do governo de quase 40 anos de José Eduardo dos Santos, que finalmente ocorreu em 2017. Como diria Balandier (1994) sobre a política como representação e como dramatização, o poder político obtém a subordinação por meio da teatralidade, utilizando meios espetaculares, assim como a contra política deve também fazer-se política de imagem e da imaginação para produzir efeitos capazes de suscitar emoções (1994, p. 117). Ou seja, as formas de ativismo e protesto dos Revús, carregados de simbolismos e de criatividade, contribuíram para dar visibilidade aos jovens da geração digital em Angola como agentes reconhecidos na seara política, criando possibilidades de subverter a subordinação governamental e geracional - se contrapondo a sua teatralidade hegemônica - ao se colocarem em cena e ao utilizarem da linguagem e das ferramentas estéticas ao seu dispor.

\section{Considerações finais}

Na última década, as formas de ativismos e protestos se diversificaram em causas, lugares, criatividade e formatos de intervenção, carregando como características marcantes o advento das tecnologias móveis de captação de produção e edição de imagens utilizando as redes sociais como 
produtores e difusores de comunicação e informação instantâneas e alternativas aos meios hegemônicos, bem como se tornaram instrumentos de rápida mobilização e organização de eventos de rua e atos políticos nas redes.

Em diferentes países do mundo, os impactos das manifestações e protestos iniciados pelas juventudes tiveram diferentes consequências, desde a ascensão ao poder por parte de políticos conservadores e nacionalistas até a derrubada de governos autoritários ou a ascensão de políticos progressistas. Em Angola, mesmo com o desgaste, a doença e a saída de José Eduardo dos Santos do governo e as promessas de mudanças no sistema político, de renovação dos quadros, de investigação da corrupção e ampliação da democracia por parte do novo presidente, o MPLA permanece no poder e as promessas de mudanças estruturais não foram colocadas em prática. ${ }^{19}$

Dentre as peculiaridades das formas de protesto e ativismo da geração digital estão as características criativas de intervenção, a produção e o compartilhamento da própria narrativa a partir de múltiplos pontos de vista, a diluição das lideranças e as novas linguagens estetizadas de informação, com ênfase ao visual, ao sonoro, ao performático, através do uso de diferentes suportes, como os equipamentos urbanos, o próprio corpo e os equipamentos digitais, que provocam sensibilidades políticas através de estilos estéticos reconhecíveis como o realismo, a ironia, o satírico, o drama e o cômico - entre outros.

As denominações "Jovens Revús" e "15+2" foram transformadas em marcos e marcas geracionais do ativismo e do protesto em Angola. Em junho de 2020, participei como ouvinte de um evento na internet, organizado pelo 15+2, tendo como referência o marco dos passados 5 anos de quando foram presos. O tema recorrente do encontro em forma de live, através do facebook, foi o destino atual daqueles ativistas e o que eles pensam hoje, sobre o que fizeram e sobre os dias atuais. Alguns se afastaram definitivamente das pautas políticas, alegando necessitarem de tempo para cuidar das suas vidas ou da família, outros continuam suas trajetórias de envolvimento com diferentes formas de ativismo, principalmente direcionando seus esforços de crítica contra a hegemonia política do MPLA e contra a corrupção, ou na militância envolvendo a pauta de ampliação das liberdades de expressão e da democratização do sistema político em suas diferentes instâncias, a começar pelos municípios, entre outras causas, como, por exemplo, o movimento

\footnotetext{
${ }^{19}$ Por exemplo, a violência policial é considerada uma prática comum no País, atribuída ao longo, exclusivo e autoritário domínio político do mesmo partido e das mesmas pessoas no governo. Na semana em que eu estava finalizando a revisão deste artigo, começou uma grande mobilização organizada pela sociedade civil contra a violência policial em Angola, com uma crítica contundente ao novo presidente e ao MPLA. Ver: https://www.dw.com/pt-002/as-vidasangolanas-importam-jovens-exigem-fim-da-viol\%C $3 \%$ A Ancia-policial-em-angola/a-54905729 Último acesso em $13 / 09 / 2020$.
} 
"Jovens pelas Autarquias"20. Além do mais, a experiência com o ativismo levou vários deles a realizarem palestras, publicarem livros e a criarem coletivos organizados com alguma implicação política e social.

Como diria Pleyers (2013) em sua análise sobre as manifestações na Europa, em 2011, uma nova geração de ativistas descobriu novas formas de promover mudanças políticas, mediante a capacidade de comunicar-se e de organizar-se de forma autônoma, fora do alcance dos métodos atuais de controle político e econômico e com habilidade do uso de ferramentas individuais de comunicação e de produção de conteúdo. Quanto aos Revús, mesmo que nem todos e todas continuem envolvidos diretamente em atividades políticas, eles fazem parte deste processo do qual fala Pleyers. Dentre os muitos desafios analíticos que permanecem, ainda está a necessidade de entendermos o alcance de tais transformações na vida das diferentes juventudes, neste caso específico em Angola, mas também para além, e também em como será o campo da atuação e da disputa política mediadas cada vez mais pelas tecnologias digitais, por seus usuários, produtores e controladores $^{21}$, jovens ou não. Outro desafio será o de compreendermos melhor os efeitos das agências estetizadas sobre emancipação política dos sujeitos.

\section{Bibliografia}

ALONSO, Angela. "Repertório, segundo Charles Tilly: história de um conceito". En: Sociologia \& Antropologia.v.02.03, pp 21-41, 2012

ARCE, José Manuel Valenzuela. El sistema es antinosotros; culturas, movimientos y resistencias juveniles. Barcelona: Gedisa Editorial, 2015.

BALANDIER, Georges. El poder en escenas: de la representación del poder al poder de la representación. Paidós Studio: Barcelona, 1994.

BAYAT, Asef. Life as Politics. How Ordinary People Change the Middle East. Amsterdan: Amsterdan Universited Press, 2010.

CAMPOS, Ricardo, BRIGHENTI, Andrea Mubi e SPINELLU, Luciano. "Introdução". En: (org). Uma Cidade de Imagens. Produções e Consumos Visuais em Meio Urbano. Lisboa: Mundos Sociais, 2011.

CASTELLS, Manuel. Redes de indignacion y esperanza: los movimientos sociales en la era de internet. Madrid: Alianza Editorial, 2012.

\footnotetext{
${ }^{20}$ Ver: https://www.facebook.com/jovenspelasautarquias Último acesso em 10/9/2020.

${ }^{21}$ Como é o caso dos novos usos das tecnologias de acesso e manipulação dos dados na internet por parte das grandes empresas do ramo digital, que estão servindo também aos governos e grandes grupos políticos.
} 
FEIXA, Carles. De la generación @ a la \# generación: la juventud en la era digital. Barcelona, NED, 2014.

HEBDIGE, Dick. Hiding in the light. London: Routledge, 1988;

HONWANA, Alcinda. "Juventude, Waithood e Protestos Sociais em Africa". En: BRITO, Luís, de; CASTEL-BRANCO, Carlos Nuno; CHICHAVA, Sérgio; FORQUILHA, Salvador; FRANCISCO, Antonio (Org). Desafios para Moçambique - 2014. Maputo: IESE, 2014.

LIPOVETSKY, G. e SERROY, J. A estetização do mundo: viver na era do capitalismo artista. São Paulo: Companhia das Letras, 2015.

MANOEL, Coque Francisco; FORTUNA, Cláudio dos Anjos Ramos. Os Meandros das Manifestações em Angola. Brasília, Kiron, 2012.

MARCON, F. "Agências Estetizadas, Geração Digital, Ativismos e Protestos no Brasil". Ponto Urbe, v. 23, 2018, p. 1-19.

MARCON, F.; TOMAS, C. Kuduro, Juventude e Estilo de Vida: Estética da Diferença e Cenário de Escassez. Tomo (UFS), v. 21, p. 137-167, 2012.

PLEYERS, Geoffrey. 2013. "Ativismo das ruas e on-line dos movimentos pós-2011”. Lutas Sociais, São Paulo, vol.17 n.31, jul./dez: 87-96.

ROCHA, Everardo e PEREIRA, Carla. "Sociabilidade e novas tecnologias: os significados do consumo entre jovens". En: ROCHA, Everardo, PEREIRA, Cláudia e BARROS, Carla (orgs). Cultura e experiência midiática. Rio de Janeiro: Ed. PUC/Rio; Mauad, 2014.

SILVA, Sandra Rubia da. "De afetos e de memórias: o consumo do telefone celular como "tecnologia afetiva"'. En: RIAL, Carmen, SILVA, Sandra R. e SOUZA, Angel Maria de (org). Consumo e Cultura Material: perspectivas etnográficas. Florianópolis: Ed. UFSC, 2012.

SILVA, Regina Helena Alves da (org). Ruas e Redes: dinâmicas dos protestos BR. Belo Horizonte: Autêntica, 2014. 